\title{
Control of Morphology and Acidity of SAPO-5 for the Methanol-To- Olefins (MTO) Reaction
}

Kazusa Terasaka, Hiroyuki Imai* and Xiaohong Li

Faculty of Environmental Engineering, The University of Kitakyushu, 1-1 Hibikino, Wakamatsu, Kitakyushu, Fukuoka, Japan

\begin{abstract}
Silicoaluminophosphate (SAPO) zeotype materials, a family of zeolites with micropores, have moderate acid strengths compared with conventional aluminosilicate zeolites; furthermore, their acid amounts can be tuned by the incorporation of Si species into the aluminophosphate (AIPO) framework. The conversion of methanol to light olefins including ethene, propene, and butenes (isobutene, 1-butene, and 2-butenes), methanol-to-olefins (MTO) reaction, is carried out over zeolites as an acid catalyst. In the MTO reaction, the enhancement of the diffusivity of reactants and products and the tuning of the acidity of zeolites are crucial keys to the improvement of the catalyst life due to the suppression of the coke deposition in the pores. In the present study, we have focused on the improvement of the catalytic performance of SAPO- 5 materials with the AFI structure with large micropores of $0.73 \mathrm{~nm}$ apertures in the MTO reaction. Highly crystalline SAPO-5 with different morphologies and acidities were readily synthesized by merely varying the concentration of the starting gel. The employment of a highly concentrated starting gel with a $\mathrm{H}_{2} \mathrm{O} / \mathrm{Al}$ ratio of 5 led to the formation of smaller-sized SAPO- 5 crystallites with a larger amount of mild acid sites compared with SAPO- 5 synthesized with the conventional compositions with the $\mathrm{H}_{2} \mathrm{O} / \mathrm{Al}$ ratio of 50 . The catalytic performance of the synthesized SAPO-5 materials as an acid catalyst was evaluated in the MTO reaction. The crystallite morphology as well as the acid amount scarcely affected the initial activity and product distribution, while the catalyst life was considerably affected. The decrease in the crystallite size of SAPO-5 led to improving the catalyst life due to the improvement of the resistance to the coke deposition.
\end{abstract}

Keywords: AFI-type silicoaluminophosphate; SAPO-5; Crystallite size; Acidity; Methanol-to-olefins (MTO) reaction; Gel concentration

\section{Introduction}

Accompanying an increase in worldwide energy consumption, the utilization of carbon resources alternative to crude oil, such as biomass, coal and natural gas, has been highly desired for the production of chemicals. Methanol is one of attractive materials as a sustainable feedstock for the production of increasingly-demanded hydrocarbons in industrial processes because methanol can be industrially manufactured by the conversion of syngas obtained through the gasification of various carbon resources, and be readily converted to hydrocarbons over solid acid catalysts. Thus, the conversion of methanol to light olefins including ethene, propene and butenes has attracted much attention in recent decades [1]; so-called "methanolto-olefins (MTO) reaction". The MTO reaction is generally carried out over zeolites or zeotype materials with strong Brønsted acid sites and micropores as well as internal cavities. Among the zeolite catalysts, silicoaluminophosphate zeotype material SAPO-34 with the CHA structure, which is composed of a 3-dimensional pore system with 8 -membered ring $(8-\mathrm{MR})$ openings $(0.38 \mathrm{~nm} \times 0.38 \mathrm{~nm})$ [2], is wellknown as an excellent catalyst for the MTO reaction; it provides high yields of light olefins with a long catalyst life due to moderate acid strength and the limitation of the size of the products imposed by the small pores [1,3-7].

It has been proposed that the formation of hydrocarbon pool species, alkylated aromatic compounds such as hexamethylbenzene, in the cages of SAPO-34 should be required for the production of light olefins during the MTO reaction [8-11]. Meanwhile, the formation of the bulky aromatic compounds in the cage leads to the formation of coke through the further polymerization to cause the rapid deactivation due to the regulation of the diffusion of reactants as well as products [12]. Therefore, improving the resistance to the coke deposition is required for the utilization of zeolite catalysts for a longer period. The catalyst life is strongly influenced by the crystallite size of zeolites. In fact, the catalyst life of SAPO-34 can be improved by decreasing the crystallite size without varying the acid amount due to the improvement in the mass transfer inside the pores of the catalyst $[7,13]$. The synthesis of smaller-sized SAPO-34 compared with SAPO34 synthesized by the conventional method has been attained by using various approaches, such as dry-gel method and microwave-assisted heating [14-22]. These smaller-sized SAPO-34 catalysts exhibited a longer catalyst life compared with the conventional SAPO-34 catalyst in the MTO reaction. A facile method for preparing the nano-sized crystallites of ZSM-5 was developed by enhancing the nucleation by mixing the starting gel under moderate conditions before the crystallization [23]. Furthermore, the control of the crystallite size of ZSM- 5 can be attained by merely changing the water content in the starting amorphous gel. The nano-sized ZSM-5 exhibited an excellent catalytic performance in the hexane cracking and higher resistance to the coke deposition compared with conventional micro-sized ZSM-5 catalysts. The facile method with controlling the gel concentration is expected to be applied to the synthesis of a variety of zeolite catalysts to form smaller-sized crystallites for improving catalytic performances.

Recently, silicoaluminophosphate zeotype material with the AFI topology, SAPO-5, has been used as a model catalyst for investigating detailed mechanisms of the MTO reaction. SAPO- 5 consists of a

*Corresponding author: Hiroyuki Imai, Faculty of Environmental Engineering, The University of Kitakyushu, 1-1 Hibikino, Wakamatsu, Kitakyushu, Fukuoka 808-0135 Japan, Tel: +81-93-695-3733; Fax: +81-93-695-3398; E-mail: h-imai@kitakyu-u.ac.jp

Received August 28, 2015; Accepted October 28, 2015; Published November 03, 2015

Citation: Terasaka K, Imai H, Li X (2015) Control of Morphology and Acidity of SAPO-5 for the Methanol-To-Olefins (MTO) Reaction. J Adv Chem Eng 5: 138. doi:10.4172/2090-4568.1000138

Copyright: ( 2015 Terasaka K, et al. This is an open-access article distributed under the terms of the Creative Commons Attribution License, which permits unrestricted use, distribution, and reproduction in any medium, provided the original author and source are credited. 
1-dimensional pore system with 12 -membered ring (12-MR) openings $(0.73 \mathrm{~nm} \times 0.73 \mathrm{~nm})$ [2], whose diameter is similar to that of the cavities of SAPO-34. Thus, bulky compounds would be capable of diffusing in and out of the catalyst through the large pore openings. In fact, comparing SAPO-5 with SAPO-34 in the MTO reaction, large-sized alkenes were preferentially formed as an intermediate molecule in the micropores of SAPO- 5 to produce mainly butenes, in particular isobutene, through the decomposition of the intermediate alkenes [24,25]. By contrast, ethene and propene were selectively produced through the formation of bulky aromatic compounds over SAPO-34 [26]. Since even light olefins can be distinguished by the size of micropore aperture, SAPO5 has an advantage over SAPO-34 in respect of the production of butenes from methanol. Furthermore, the absence of cavities and intersections in SAPO- 5 facilitates the estimation of the space available for the formation of intermediates and products in the MTO reaction. In addition to the control of the product distribution, the large pore openings of SAPO- 5 would be advantageous to suppressing the coke deposition due to lower diffusion barriers of molecules in comparison with zeolites with small pores. Meanwhile, the diversification of SAPO5 by tuning the acidity and/or the crystallite morphology and size has not been well-studied for improving the catalytic performance in the MTO reaction. It is expected that the investigation of the catalytic properties of SAPO- 5 with different physicochemical properties would lead to the promotion of the potential of SAPO-5 as an acid catalyst in the MTO reaction.

In the present study, we report on the synthesis of SAPO- 5 catalysts with different morphologies as well as acidities. In particular, we aimed to develop a facile synthesis method for decreasing the crystallite size of SAPO-5. Then, the synthesized SAPO- 5 catalysts were applied as an acid catalyst to the MTO reaction in order to investigate the catalytic performance of the SAPO-5 catalysts. In addition, we also investigated the effects of the crystallite morphology and acidities on the catalytic performance on the basis of the activity, the product distribution, and the catalyst life.

\section{Experimental}

\section{Synthesis of SAPO-5 materials with different morphologies}

The SAPO-5 materials with different morphologies were hydrothermally synthesized with water, $\mathrm{Al}\left(\mathrm{O}^{i} \mathrm{Pr}\right)_{3}$ (Kanto Chem. Co.) as an $\mathrm{Al}$ source, orthophosphoric acid $\left(\mathrm{H}_{3} \mathrm{PO}_{4}, 85 \%\right.$, Kanto Chem. Co.) as a $\mathrm{P}$ source, fumed silica (Aerosil 200, Aerosil) as a Si source and tetraethylamine (TEA, Tokyo Chem. Inc.) as an organic-structuredirecting agent (OSDA). $\mathrm{Al}\left(\mathrm{O}^{i} \mathrm{Pr}\right)_{3}$ was added to an aqueous solution containing $\mathrm{H}_{3} \mathrm{PO}_{4}$ and TEA to form a white suspension. Fumed silica was added to the mixture. The molar composition of the prepared amorphous gel was $1 \mathrm{Al}_{2} \mathrm{O}_{3}: 1 \mathrm{P}_{2} \mathrm{O}_{5}: 0.2 \mathrm{SiO}_{2}: 1.0$ TEA: $10-100 \mathrm{H}_{2} \mathrm{O}$. The prepared gel was transferred into a Teflon-lined stainless steel vessel and hydrothermally treated at $473 \mathrm{~K}$ for 2 days with tumbling at 30 $\mathrm{rpm}$. The obtained product was recovered by filtration, washed with deionized water, and dried at $363 \mathrm{~K}$. Then, the final product of SAPO-5 was obtained by calcination of the as-synthesized sample at $823 \mathrm{~K}$ for $10 \mathrm{~h}$ for removing the OSDA. For the purpose of varying crystallite sizes of SAPO-5, $5 \mathrm{wt} \%$ SAPO- 5 product, which was synthesized with a $\mathrm{H}_{2} \mathrm{O} / \mathrm{Al}$ ratio of 10 , as a seed was added to the initial amorphous gel.

\section{Characterization}

XRD patterns were collected on a SmartLab (Rigaku) instrument using a $\mathrm{Cu}-\mathrm{Ka} \mathrm{X}$-ray source $(45 \mathrm{kV}, 200 \mathrm{~mA})$. Nitrogen adsorptiondesorption measurements were conducted at $77 \mathrm{~K}$ on a BELSORP-mini II (MicrotracBEL Corp.) instrument. Prior to the measurement, the sample was evacuated at $623 \mathrm{~K}$ for $2 \mathrm{~h}$. The BET (Brunauer-EmmettTeller) specific surface area was calculated from the adsorption data. External surface area was estimated by the $t$-plot method. Field-emission scanning microscopic (FE-SEM) images of the samples were obtained on an S-5200 microscope (Hitachi) operating at $1.0 \mathrm{kV}$. Elemental analyses of the samples were performed on an inductively coupled plasma-atomic emission spectrometer (ICP-AES, PerkinElmer). Ammonia temperature-programmed desorption ( $\mathrm{NH}_{3}$-TPD) profiles of the samples were recorded on a BELCAT (MicrotracBEL Corp.) apparatus. Typically, the sample was pretreated at $773 \mathrm{~K}$ in $\mathrm{He}(50 \mathrm{~mL}$ $\mathrm{min}^{-1}$ ) for $1 \mathrm{~h}$ and then was cooled to $373 \mathrm{~K}$. Then, $10 \% \mathrm{NH}_{3}$ in He was allowed to make contact with the sample for $30 \mathrm{~min}$. Subsequently, the sample was evacuated to remove weakly adsorbed $\mathrm{NH}_{3}$ for $15 \mathrm{~min}$ at $373 \mathrm{~K}$. Finally, the sample was heated up to $773 \mathrm{~K}$ at a ramping rate of $10 \mathrm{~K} \mathrm{~min}^{-1}$ with the He flow $\left(50 \mathrm{~mL} \mathrm{~min}{ }^{-1}\right)$ passed through the reactor. A mass spectrometer was used to monitor desorbed $\mathrm{NH}_{3}(m / e=16)$.

\section{Methanol-to-Olefins (MTO) reaction}

The MTO reaction was carried out in a 0.25 in. (OD) quartz tubular flow microreactor loaded with $100 \mathrm{mg}$ of 50/80 mesh zeolite pellets without a binder. The catalyst was centered at a quartz reactor in a furnace. The catalyst was pretreated at $500^{\circ} \mathrm{C}$ for $1 \mathrm{~h}$ in the stream of $\mathrm{N}_{2}$ prior to the reaction, and then the reactor was cooled to $450^{\circ} \mathrm{C}$. The initial partial pressure of methanol was set at $2.6 \mathrm{kPa}$. $\mathrm{N}_{2}$ gas was used as a carrier. The catalyst weight to the flow rate ratio $\left(\mathrm{W} / \mathrm{F}_{\text {-methanol }}\right)$ was $67.5 \mathrm{~g}_{\text {-cat }} \mathrm{h}\left(\mathrm{mol}_{\text {-methanol }}\right)^{-1}$, which corresponded to the weight hourly space velocity of methanol (WHSV) of $0.47 \mathrm{~h}^{-1}$.

The reaction products were analyzed with an on-line gas chromatograph (Shimadzu GC-2014) with a flame ionization detector and a capillary column (HP-PLOT $30 \mathrm{~m} \times 0.53 \mathrm{~mm}, 6 \mu \mathrm{m}$ film thickness). The selectivities to the products were calculated based on the carbon numbers.

\section{Results and Discussion}

\section{Synthesis of SAPO-5 with different morphologies}

Figure 1 shows XRD patterns of the samples obtained through the hydrothermal treatment with the molar ratio of $\mathrm{H}_{2} \mathrm{O} / \mathrm{Al}$ varied from 5 to 50 in the starting gel and the following calcination. All the samples exhibited the XRD pattern typical of the AFI structure with high crystallinity, and showed almost the same XRD pattern although a small peak derived from another phase appeared at $22^{\circ}$ in the pattern of the sample synthesized with the $\mathrm{H}_{2} \mathrm{O} / \mathrm{Al}$ ratio of 5 . It is indicated that the concentration of the starting gel hardly affected the crystallinity of the silicoaluminophosphate zeotype material with the AFI topology. The crystallinity of the samples was further investigated by evaluating the intensities of the XRD diffraction lines attributed to the (100), (210), (002), and (102) planes of the AFI structure. The relative intensities of the diffraction lines of the samples are summarized in Figure 2. As the $\mathrm{H}_{2} \mathrm{O} / \mathrm{Al}$ ratio in the starting gel increased, the intensity of the diffraction line derived from the (002) plane increased in comparison with those from the (100), (210), and (102) planes. Moreover, the larger increase in the relative intensity of the (002) diffraction line to the (210) diffraction line was observed in comparison with that of (002) to (102). Since the 1-dimensional (1-D) pore system of the AFI structure is arranged along the $c$-direction [2], it is suggested that the pore length of SAPO-5 can be shortened through the crystallization with highly concentrated starting gels.

The morphology of the samples was evaluated by FE-SEM observations (Figure 3). All the samples, except for the sample 


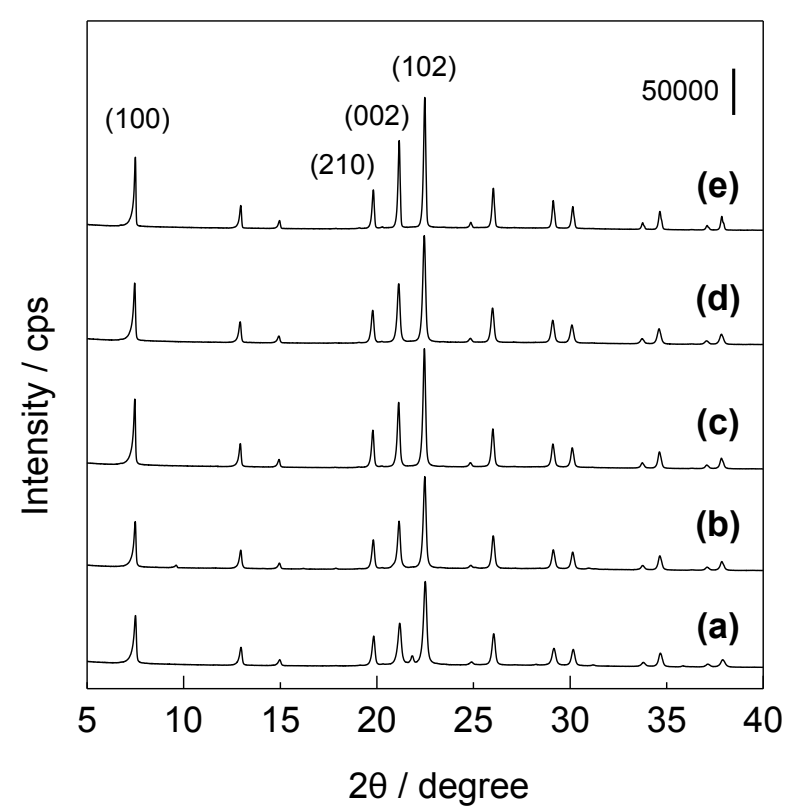

Figure 1: XRD patterns of the samples synthesized with the molar ratio of $\mathrm{H}_{2} \mathrm{O} / \mathrm{Al}$ in the starting gel: (a) 5, (b) 10 , (c) 10 (with $5 \mathrm{wt} \%$ seed), (d) 25, and (e) 50 .

synthesized with the $\mathrm{H}_{2} \mathrm{O} / \mathrm{Al}$ ratio of 5 in the starting gel, were composed of hexagonal crystallites. In the synthesis with the $\mathrm{H}_{2} \mathrm{O} / \mathrm{Al}$ ratio of 50 in the starting gel, the huge crystallites were formed with mostly around $16 \mu \mathrm{m}$ in diameter and $8 \mu \mathrm{m}$ in length. The crystallite size was decreased with the decrease in the water content in the gel; the average sizes were found to be $4 \mu \mathrm{m}$ in diameter and $0.7 \mu \mathrm{m}$ in length for the $\mathrm{H}_{2} \mathrm{O} / \mathrm{Al}$ ratio of 25. By contrast, the crystals grew along the $c$-direction through the crystallization with the $\mathrm{H}_{2} \mathrm{O} / \mathrm{Al}$ ratio of 10 although the crystallite diameter was decreased to be $3 \mu \mathrm{m}$. When the sample synthesized with the $\mathrm{H}_{2} \mathrm{O} / \mathrm{Al}$ ratio of 10 was employed as a seed for the synthesis with the $\mathrm{H}_{2} \mathrm{O} / \mathrm{Al}$ ratio of 10 , the crystal growth along the $c$-direction was suppressed and the hexagonal plates with around 2 $\mu \mathrm{m}$ in diameter and 0.1-0.3 $\mu \mathrm{m}$ in length were formed. Interestingly, the hexagonal-cylindrical crystallites of the seed was no longer observed after the crystallization of the gel containing the seed, indicating that the seed crystals were mostly dissolved during the hydrothermal treatment. The further decrease in the water content drastically changed the crystallite morphology; large agglomerates composed of plate-like crystallites were formed (Figures $3 \mathrm{a}$ and $3 \mathrm{~b}$ ). Considering our findings above, the SAPO-5 materials with the different morphologies can be readily synthesized by merely changing the water content in the starting gel under the present hydrothermal conditions. It has been reported that the higher alkalinity favored the nucleation of a lot of particles due to the easy-dissolution of silicon and aluminium sources in the solution, forming the smaller-sized zeolite $[27,28]$. In addition, the increase in the concentration of the starting gel leads to increasing a nucleation density in the early stages of the crystallization to make the crystallite size reduced [29]. Thus, decreasing the water content in the starting gel, which corresponds to the increasing the gel concentration, would lead to the enhancement of the nucleation in the early stage of the crystallization due to accelerating the dissolution of the silicon and aluminium sources in the increased $\mathrm{pH}$ solution, resulting in the formation of the smaller-sized SAPO-5 crystallites. Furthermore, the nucleation followed by the crystallization may be promoted on the surface of the seed crystallites to form the smaller-sized SAPO-
5 crystallites in comparison with the crystallites synthesized in the absence of the seed crystallites even when there is no difference in the gel concentration.

The physicochemical properties of the samples synthesized with the various water contents are summarized in Table 1 . The samples synthesized with the $\mathrm{H}_{2} \mathrm{O} / \mathrm{Al}$ ratios set at $5,10,25$ and 50 are denoted by $S(5), S(10), S(25)$ and $S(50)$, respectively. The BET specific surface area of the samples was independent of the gel concentration although the external surface area was well-relevant to the crystallite size of the samples; the external surface area was increased with the decrease in the crystallites size. Since smaller-sized crystallites were agglomerated to form larger-sized crystallites, the differences in the BET surface areas may be derived from the heterogeneity of the crystallite size in the large agglomerates.

All the samples, except for $\mathrm{S}(50)$, contained almost the same compositions of $\mathrm{Si}, \mathrm{Al}$, and $\mathrm{P}$; moreover, the $\mathrm{Si} / \mathrm{Al}$ ratios in the samples were similar to those in the corresponding starting gel. By contrast, when the water content was increased to the $\mathrm{H}_{2} \mathrm{O} / \mathrm{Al}$ ratio of 50 , the $\mathrm{Si}$ content in the sample was increased; simultaneously, the $\mathrm{Al}$ and $\mathrm{P}$ contents were relatively decreased. Roldán et al. have reported that in the synthesis of SAPO-5, Si species are incorporated into the AlPO framework through the substitution of one $\mathrm{Si}^{4+}$ for one $\mathrm{P}^{5+}$ in the starting gel with high $\mathrm{pH}$, while silica islands can be formed as a result of the substitution of two $\mathrm{Si}^{4+}$ for one $\mathrm{P}^{5+}$ and one $\mathrm{Al}^{3+}$ in the starting gel with low $\mathrm{pH}$ [30]. Thus, it is suggested that $\mathrm{Si}$ species were incorporated into the AlPO framework in replace of $\mathrm{P}$ species, independent of the water content in the range of the $\mathrm{H}_{2} \mathrm{O} / \mathrm{Al}$ ratio of 5-25 due to the dissolution of Si species in the concentrated gel. In the case of low concentration of starting gels, $\mathrm{pH}$ in the gel would be decreased to decrease the solubility of $\mathrm{Si}$ species, leading to the promotion of the formation of $\mathrm{Si}-\mathrm{O}-\mathrm{Si}$ networks through the substitution of two $\mathrm{Si}^{4+}$ for one $\mathrm{P}^{5+}$ and one $\mathrm{Al}^{3+}$.

$\mathrm{NH}_{3}$-TPD measurements were performed in order to study the acidity of the samples. The results are shown in Figure 4 and Table 1. Two large peaks were overlapped in the $\mathrm{NH}_{3}$-TPD profiles of all the samples; a peak was observed at around $440 \mathrm{~K}$ and the other at around $523 \mathrm{~K}$ (Figure 4). The low-temperature peak corresponds to $\mathrm{NH}_{3}$ adsorbed on non-acidic - $\mathrm{OH}$ groups and $\mathrm{NH}_{4}^{+}$, which forms by the reaction of $\mathrm{NH}_{3}$ with Brønsted acid sites (BASs), and does not correspond to $\mathrm{NH}_{3}$ adsorbed on catalytically active BASs and Lewis acid sites (LASs) [31,32]. On the other hand, the high-temperature peak corresponds to the $\mathrm{NH}_{3}$ desorption from catalytically active BASs and LASs. The high-temperature peak of the product increased with the decrease in the water content in the starting gel, and the temperature where the peak top was observed was almost unchanged. The addition of the seed crystals to the starting gel also resulted in virtually increasing the high-temperature peak as $S(10)$ was compared with S(10)-seed; simultaneously, a shoulder peak was observed at around $623 \mathrm{~K}$, indicating that strong acid sites were newly formed compared with the products synthesized in the absence of seed crystals. Furthermore, the area ratio of the high-temperature peak to the lowtemperature peak decreased with the decrease in the water content in the gel. The acid amounts of the products estimated from the hightemperature peak are listed in Table 1. In SAPO molecular sieves, the acid sites are generated by the incorporation of $\mathrm{Si}$ species into the AlPO framework [33-35]. In the case of the replacement of $\mathrm{P}$ species alone in the AlPO framework by $\mathrm{Si}$ species, Si species should be surrounded by $\mathrm{Al}$ species to give rise to relatively weaker BASs. By contrast, the substitution of two $\mathrm{Si}^{4+}$ for neighboring $\mathrm{P}^{5+}$ and $\mathrm{Al}^{3+}$ is prone to form silica islands, and stronger acid sites are generated at the boundaries of silica islands. Simultaneously, the formation of silica islands decreases 


\begin{tabular}{|c|c|c|c|c|c|c|c|}
\hline Sample & $\mathrm{H}_{2} \mathrm{O} / \mathrm{Al}$ in gel & $\begin{array}{l}\text { S.A. }{ }^{- \text {BET }^{a}} \\
/ \mathbf{m}^{2} \mathbf{g}^{-1}\end{array}$ & $\begin{array}{l}\text { S.A. }{ }_{\text {-ExT }}{ }^{a} \\
/ \mathbf{m}^{2} \mathbf{g}^{-1}\end{array}$ & $S i / A I^{b}$ & $\mathbf{P} /\left.\mathbf{A}\right|^{\mathrm{b}}$ & $\mathrm{Si} /(\mathrm{Al}+\mathrm{P}+\mathrm{Si})^{\mathrm{b}}$ & $\begin{array}{l}\text { Acid amount } \\
/ \mathrm{mmol} \mathrm{g}^{-1}\end{array}$ \\
\hline$S(5)$ & 5 & 304 & 36 & 0.11 & 0.85 & 0.054 & 0.367 \\
\hline$S(10)$ & 10 & 289 & 12 & 0.11 & 0.87 & 0.056 & 0.301 \\
\hline$S(10)$-seed & 10 (with seed) & 267 & 23 & 0.11 & 0.91 & 0.052 & 0.366 \\
\hline$S(25)$ & 25 & 245 & 3.6 & 0.10 & 0.92 & 0.050 & 0.296 \\
\hline$S(50)$ & 50 & 278 & 7.9 & 0.13 & 0.83 & 0.069 & 0.238 \\
\hline
\end{tabular}

aEstimated by $\mathrm{N}_{2}$ adsorption-desorption method

${ }^{b}$ Measured by ICP-AES

'Estimated from $\mathrm{NH}_{3}$-TPD measurement

Table 1: Physicochemical properties of the samples synthesized with various water contents.

the amount of the acid sites in SAPO materials in comparison with the amount of the acid sites derived from $\mathrm{Si}$ species surrounded by $\mathrm{Al}$ species [36-39]. Thus, in the highly concentrated gels, Si species would be homogeneously incorporated into the framework with surrounded by $\mathrm{Al}$ species to generate relatively weak acid sites. On the other hand, in the low-concentrated gels, relatively strong acid sites would be generated by the formation of silica islands due to the incorporation of larger amounts of Si species. Indeed, S(50), which was synthesized with the lowest-concentrated gel, contained the highest $\mathrm{Si}$ content and the smallest acid amount among the samples (Table 1). Except for S(50), the acid amount of the samples was strongly dependent on the gel concentration, indicating that there are some differences in the Si distribution in the framework among the samples although all the samples contained similar $\mathrm{Si}$ amounts to those in the starting gels. However, since the acid sites attributed to the high-temperature peak were classified as weak BASs and the Si content in the samples was low, it is difficult to clarify the slight differences in the acid strengths derived from the Si distribution in the samples in detail. It is probable that the seed would also contribute to the homogeneous distribution of $\mathrm{Si}$ species in preference to the formation of silica islands due to the enhancement of the nucleation, resulting in the generation of the acid sites derived from $\mathrm{Si}$ species surrounded by $\mathrm{Al}$ species.

\section{Catalytic performance of SAPO-5 catalysts in the methanol- to-olefins (MTO) reaction}

The catalytic properties of the prepared SAPO- 5 samples as an acid catalyst were evaluated in the MTO reaction. The results are shown in Figures 5 and 6 and Table 2. Figure 5 shows the methanol conversion over the prepared SAPO- 5 catalysts as a function of time on stream. All the catalysts exhibited $100 \%$ methanol conversion in the initial stage of the reaction (at $3 \mathrm{~min}$ ). A fast deactivation occurred over $S(50)$ in the initial stage of the reaction, and the methanol conversion was decreased along with the reaction time. By contrast, $S(5)$ exhibited the longest catalyst life among the catalysts; complete methanol conversion was kept for $5 \mathrm{~h}$ after the reaction started. The catalyst life was increased in line with the following order: $S(5)>S(10)$-seed $>S(10)>S(25)>S(50)$, which is consistent with the order of the acid amounts estimated from the $\mathrm{NH}_{3}$-TPD profiles (Table 1). In addition, the order of the catalyst life is opposite to that of the crystallite sizes of the catalysts, except for $S(5)$ : $S(50)>S(25)>S(10)>S(10)$-seed. In the MTO reaction, the effects of acidic properties and the crystallite size of zeolite catalysts on the catalyst life has been investigated in detail. The polymerization of carbonaceous species for the coke deposition in/on zeolites can be enhanced on strong acid sites, in spaces with high acid densities, and in long micropores. It has been reported that the decrease in the $\mathrm{Si}$ content, corresponding to the decrease in the acid density, of SAPO34 leads to improving the coking resistance to increase the catalyst life [7]. Furthermore, the crystallite size is a strongly important factor for improving the catalyst life compared with the acid density; the decrease in the crystallite size leads to the increase in the catalyst life $[7,37]$.
According to the findings reported above, it is indicated that in the present study the catalyst life was affected by the crystallite size of the catalysts; the smaller-sized catalyst can exhibit the longer catalyst life due to the suppression of the coke deposition by the reduction of diffusion barriers inside the micropores of the catalyst. The small amount of the acid sites of the products $\left(0.24 \mathrm{mmol} \mathrm{g}^{-1}-0.37 \mathrm{mmol} \mathrm{g}^{-1}\right)$ would hardly influence the catalyst life even if the acid amount was varied. The conversion of methanol was $100 \%$ over all the catalysts, except for S(50), for reaction time of $1 \mathrm{~h}$ (Table 2 ). All the catalysts produced propene as the main-product followed by butenes. The formation of dimethyl ether (DME) was observed over S(50), resulting from the decrease in the active sites for the conversion of DME to hydrocarbons due to the deactivation. The slight differences in the behavior of the product distributions were observed; the ratio of propene to butenes over the catalysts followed the order: $S(5)>S(10)$-seed $>S(10)>S(25)>S(50)$. In the MTO reaction, the product distribution is strongly dependent on the acid strength of zeolite catalysts. Indeed, comparing SAPO-5 with SSZ-24, which isomorphous aluminosilicate zeolite with stronger acid strength, in the MTO reaction, key reaction steps of alkene and arene cycles can display different sensitivities to acid strength [24]. By contrast, it has been reported that the product distribution is irrelative to the amount of the acid sites [40]; furthermore, the initial product distribution is independent of the crystal size of zeolite [13]. The $\mathrm{NH}_{3}-$ TPD measurement revealed that there was no significant difference in the acid strength among the catalysts since the high-temperature peaks of all the catalysts were observed at similar temperatures (Figure 4). Considering that the ratios of propene to butenes in the early stage of the reaction time were affected by the acid strength of the catalysts, fine tunings of the acid strength by controlling the Si distribution in the framework should be required for optimizing the product distribution.

Changes in the selectivities to light olefins, paraffins and DME as a function of time on stream are shown in Figure 6. All the catalysts produced mainly propene followed by butenes during the reaction. After the deactivation started, the production of DME was observed, independent of the catalysts. The selectivity to DME was drastically increased with the reaction time, while the selectivities to the other products were gradually decreased, indicating that the conversion of DME to hydrocarbons was suppressed by the deactivation due to the coke deposition on the acid sites for the transformation to hydrocarbons. During the reaction with the complete methanol conversion, no marked change in the selectivity to propene was observed. By contrast, the selectivity to butenes was gradually increased with the reaction time, and that to ethene was decreased, resulting in the decrease in propene/butenes ratios and the increase in propene/ ethene ratios over all the catalysts with the reaction time. Dahl et al. have proposed that the product distribution was affected by the increase in diffusion barriers generated by the coke deposition inside the micropores of SAPO-34 during the MTO reaction; propene/ethene ratios were decreased with the reaction time [41]. In the MTO reaction over SAPO-5, the alkene cycle is a main process for the formation 
Citation: Terasaka K, Imai H, Li X (2015) Control of Morphology and Acidity of SAPO-5 for the Methanol-To-Olefins (MTO) Reaction. J Adv Chem Eng 5: 138. doi:10.4172/2090-4568.1000138

Page 5 of 7

\begin{tabular}{|c|c|c|c|c|c|c|c|c|c|}
\hline \multirow[t]{2}{*}{ Sample } & \multirow[t]{2}{*}{ Conv. I\% } & \multicolumn{8}{|c|}{ Selectivity/C-\% } \\
\hline & & $C 2=$ & $\mathrm{C} 3=$ & $\mathrm{C} 4=$ & $\mathrm{C} 5<$ & $\mathrm{C} 1$ & $\mathrm{C} 2-\mathrm{C} 4$ & aroma $^{b}$ & DME \\
\hline$S(5)$ & 100 & 9.4 & 46.6 & 11.3 & 10.4 & 4.1 & 14.9 & 3.3 & 0 \\
\hline$S(10)$ & 100 & 9.0 & 45.9 & 15.5 & 11.7 & 4.5 & 8.5 & 4.8 & 0 \\
\hline $\begin{array}{l}S(10)- \\
\text { seed }\end{array}$ & 100 & 12.7 & 47.8 & 13.6 & 7.5 & 4.4 & 10.7 & 3.1 & 0 \\
\hline$S(25)$ & 100 & 10.4 & 43.5 & 18.6 & 9.2 & 5.7 & 9.5 & 3.2 & 0 \\
\hline$S(50)$ & 97.1 & 8.5 & 43.9 & 24.4 & 12.9 & 3.1 & 6.2 & 1.0 & 0.02 \\
\hline
\end{tabular}

aeaction conditions: cat., $100 \mathrm{mg} ; \mathrm{P}(\mathrm{MeOH}), 2.6 \mathrm{kPa} ; \mathrm{W} / \mathrm{F}=67.5 \mathrm{~g} \mathrm{~h} \mathrm{~mol}^{-1}$.

baroma=Aromatic compounds.

Table 2: The results of the MTO reaction for reaction time of $1 \mathrm{~h}$ at $450^{\circ} \mathrm{C}$.

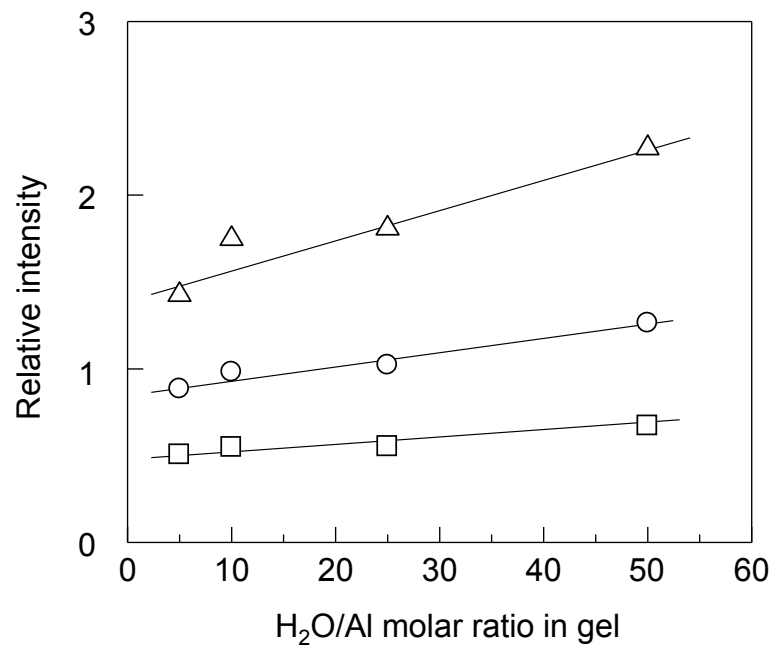

Figure 2: Relative intensities of XRD diffraction lines of SAPO- 5 as a function of the molar ratio of $\mathrm{H}_{2} \mathrm{O} / \mathrm{Al}$ in the starting gel. The intensity of the diffraction line derived from the (002) plane is relative to those from the (100), (210), and (102) planes [(०) (002)/(100), ( $\Delta)(002) /(210),(\square)(002) /(102)]$.
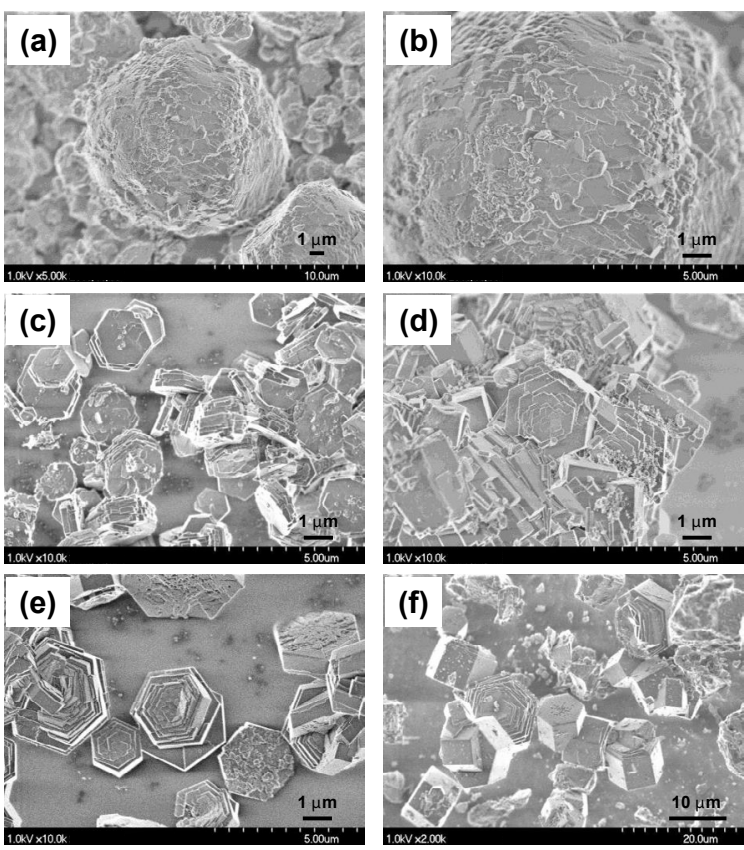

Figure 3: FE-SEM images of the samples synthesized with the molar ratio of $\mathrm{H}_{2} \mathrm{O} / \mathrm{Al}$ in the starting gel: (a, b) 5, (c) 10 (with 5 wt\% seed), (d) 10, (e) 25, and (f) 50 .

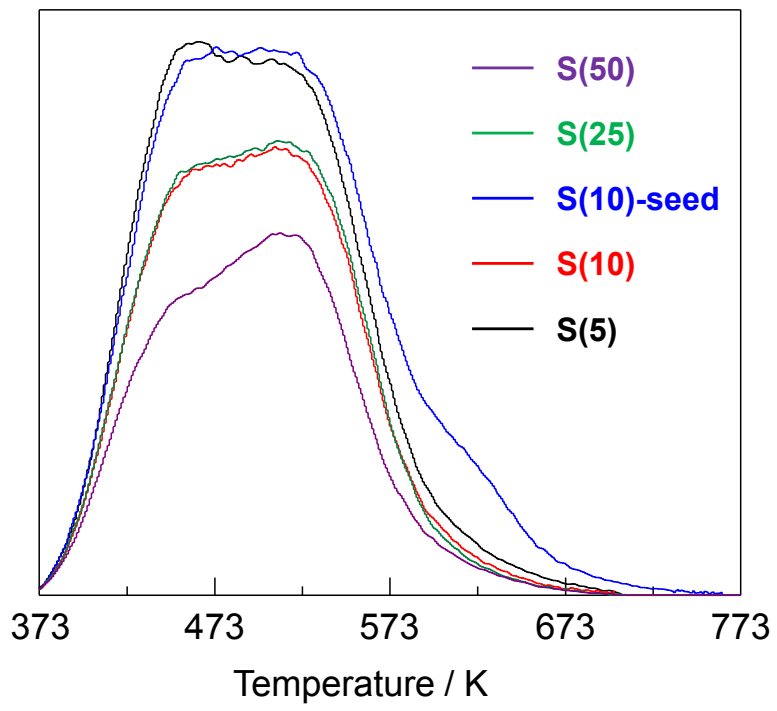

Figure 4: $\mathrm{NH}_{3}$-TPD profiles of the samples synthesized with the molar ratio of $\mathrm{H}_{2} \mathrm{O} / \mathrm{Al}$ in the starting gel.

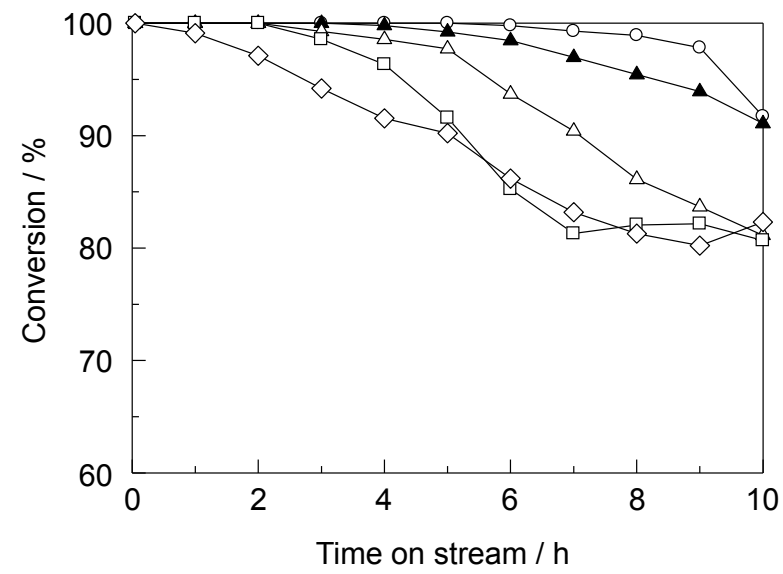

Figure 5: Methanol-to-olefins (MTO) reaction over (०) $S(5),(\Delta) S(10)$ seed, $(\Delta) S(10)$, ( $\square) S(25)$, and $(\diamond) S(50)$. Reaction conditions: cat., $100 \mathrm{mg}$; $\mathrm{P}(\mathrm{MeOH}), 2.5 \mathrm{kPa}$; W/F $=67.5 \mathrm{~g}_{\text {-cat }} \mathrm{h} \mathrm{mol}^{-1}$; reaction temp. $450^{\circ} \mathrm{C}$.

of hydrocarbons to produce selectively propene and butenes, while propene/butenes ratios are affected by the methanol conversion; the propene/butens ratios were increased with the increase in the methanol conversion as well as the reaction temperature $[24,25]$. In the present study, the micopore openings of SAPO- 5 would be too large to generate enough diffusion barriers even when the coke deposition occurred inside the micropores; furthermore, the weak acid strength of SAPO-5 

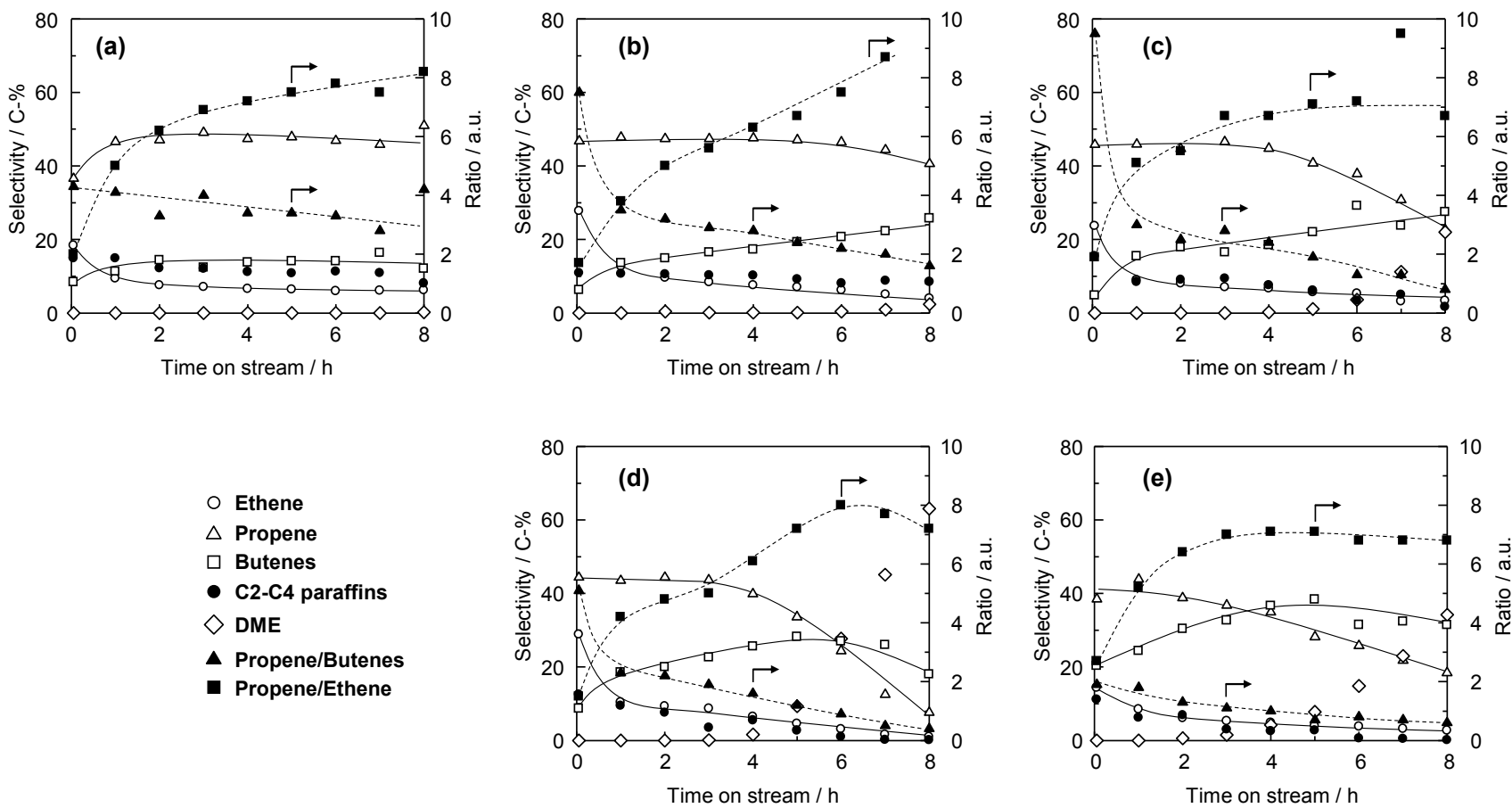

Figure 6: The product distributions in the Methanol-to-olefins (MTO) reaction over (a) S(5), (b) S(10)-seed, (c) S(10), (d) S(25), and (e) S(50). Reaction conditions: cat., $100 \mathrm{mg} ; \mathrm{P}(\mathrm{MeOH}), 2.5 \mathrm{kPa}$; $\mathrm{W} / \mathrm{F}=67.5 \mathrm{~g}_{\text {-cat }} \mathrm{h} \mathrm{mol}^{-1}$; reaction temp. $450^{\circ} \mathrm{C}$.

as evidenced by $\mathrm{NH}_{3}$-TPD measurement would cause the alkene cycle, resulting in the predominant production of propene and butenes in comparison with ethene. In addition, it is assumed that decrease in the acid sites of SAPO- 5 by the coke deposition during the MTO reaction led to decreasing the propene/butenes ratios with reaction time.

\section{Conclusion}

SAPO-5 samples with different morphologies and sizes were synthesized by tuning the water content in the starting gel, that is, the gel concentration. The gel concentration also affected the acidity of the SAPO-5 catalyst; the acid amount of the catalyst was increased with the decrease in the water content in the gel although the acid strength was mostly independent of the gel concentration. The use of the highly concentrated gel resulted in the formation of the highly-crystalline and small-sized SAPO-5 catalyst with the large amount of the acid sites. The SAPO-5 catalyst synthesized with the highly concentrated gel showed a higher stability of the catalytic activity in comparison with that with the low-concentrated gel in the MTO reaction. In addition, the SAPO5 catalyst produced predominantly propene followed by butenes with the complete conversion of methanol.

\section{References}

1. Stöcker M (2010) Methanol to Olefins (MTO) and Methanol to Gasoline (MTG): Zeolites and Catalysis. Wiley-VCH, Weinheim.

2. Baerlocher Ch, McCusker LB: Database of Zeolite Structures.

3. Stöcker M (1999) Methanol-to-hydrocarbons: catalytic materials and their behavior. Micropor Mesopor Mater 29: 3-48.

4. Stöcker M (2005) Gas phase catalysis by zeolites. Micropor Mesopor Mater 82: $257-292$

5. Yuen LT, Zones SI, Harris TV, Gallegos EJ, Auroux A (1994) Product selectivity in methanol to hydrocarbon conversion for isostructural compositions of $\mathrm{AFI}$ and CHA molecular sieves. Micropor Mater 2: 105-117.
6. Barger P (2002) Methanol to Olefins (MTO) and beyond: Zeolites for Cleaner Technologies. Imperial College Press, London.

7. Wilson S, Barger $P$ (1999) The characteristics of SAPO-34 which influence the conversion of methanol to light olefins. Micropor Mesopor Mater 29: 117-126.

8. Haw JF, Song W, Marcus DM, Nicholas JB (2003) The mechanism of methanol to hydrocarbon catalysis. Acc Chem Res 36: 317-326.

9. Arstad B, Kolboe $S$ (2001) The reactivity of molecules trapped within the SAPO-34 cavities in the methanol-to-hydrocarbons reaction. J Am Chem Soc 123: 8137-8138.

10. Haw JF, Marcus DM (2005) Well-defined (supra)molecular structures in zeolite methanol-to-olefin catalysis. Top Catal 34: 41-48.

11. Song W, Fu H, Haw JF (2001) Selective Synthesis of Methylnaphthalenes in HSAPO-34 Cages and Their Function as Reaction Centers in Methanol-toOlefin Catalysis. J Phys Chem B 105: 12839-12843.

12. Kvisle S, Fuglerud T, Kolboe S, Olsbye U, Lillerud KP, et al. (2008) Handbook of heterogeneous catalysis. Wiley-VCH, Weinheim.

13. Chen D, Moljord K, Fuglerud T, Holmen A (1999) The effect of crystal size of SAPO-34 on the selectivity and deactivation of the MTO reaction. Micropor Mesopor Mater 29: 191-203.

14. Lin S, Li J, Sharma RP, Yu J, Xu R (2010) Fabrication of SAPO-34 crystals with different morphologies by microwave heating. Top Catal 53: 1304-1310.

15. Hirota $Y$, Murata K, Tanaka S, Nishiyama N, Egashira Y, et al. (2010) Dry gel conversion synthesis of SAPO-34 nanocrystals. Mater Chem Phys 123: 507509.

16. Álvaro-Muñoz T, Márquez-Álvarez C, Sastre E (2013) Enhanced stability in the methanol-to-olefins process shown by SAPO-34 catalysts synthesized in biphasic medium. Catal Today 215: 208-215.

17. Álvaro-Muñoz T, Márquez-Álvarez C, Sastre E (2012) Use of different templates on SAPO-34 synthesis: effect on the acidity and catalytic activity in the MTO reaction. Catal Today 179: 27-34.

18. Pengfei $W$, Dexing $Y$, Jie H, Jing'an $X$, Guanzhong $L$ (2013) Synthesis of SAPO-34 with small and tunable crystallite size by two-step hydrothermal crystallization and its catalytic performance for MTO reaction. Catal Today 212 62e1-62e8. 
Citation: Terasaka K, Imai H, Li X (2015) Control of Morphology and Acidity of SAPO-5 for the Methanol-To-Olefins (MTO) Reaction. J Adv Chem Eng 5: 138. doi:10.4172/2090-4568.1000138

19. Yang M, Tian P, Wang C, Yuan Y, Yang Y, et al. (2014) A top-down approach to prepare silicoaluminophosphate molecular sieve nanocrystals with improved catalytic activity. Chem Commun (Camb) 50: 1845-1847.

20. Álvaro-Muñoz T, Sastre E, Márquez-Álvarez C (2014) Microwave-assisted synthesis of plate-like SAPO-34 nanocrystals with increased catalyst lifetime in the methanol-to-olefin reaction. Catal Sci Technol 4: 4330-4339.

21. Yang G, Wei Y, Xu S, Chen J, Li J, et al. (2013) Nanosize-enhanced lifetime of SAPO-34 catalysts in methanol-to-olefin reactions. J Phys Chem C 117: 82148222.

22. Li Z, Martínez-Triguero J, Concepción P, Yu J, Corma A (2013) Methano to olefins: activity and stability of nanosized SAPO-34 molecular sieves and control of selectivity by silicon distribution. Phys Chem Chem Phys 15: 14670 14680.

23. Bellón JM, Contreras LA, Pascual G, Bujan J (1999) Neoperitoneal formation after implantation of various biomaterials for the repair of abdominal wall defects in rabbits. Eur J Surg 165: 145-150.

24. Erichsen MW, Svelle S, Olsbye $U$ (2013) The influence of catalyst acid strength on the methanol to hydrocarbons (MTH) reaction. Catal Today 215: 216-223.

25. Erichsen MW, Svelle S, Olsbye U (2013) H-SAPO-5 as methanol-to-olefins (MTO) model catalyst: Towards elucidating the effects of acid strength. J Catal 298: $94-101$

26. Hereijgers BPC, Bleken F, Nilsen MH, Svelle S, Lillerud KP, et al. (2009) Product shape selectivity dominates the Methanol-to-Olefins (MTO) reaction over H-SAPO-34 catalysts. J Catal 264: 77-87.

27. Persson E, Schoeman BJ, Sterte J, Otterstedt JE (1994) The synthesis of discrete colloidal particles of TPA-silicalite-1. Zeolites 14: 557-567.

28. Brar T, France P, Smirniotis PG (2001) Control of Crystal Size and Distribution of Zeolite A. Ind Eng Chem Res 40: 1133-1139.

29. An T, An J, Yang H, Li G, Feng H, et al. (2011) Photocatalytic degradation kinetics and mechanism of antivirus drug-lamivudine in $\mathrm{TiO} 2$ dispersion. $\mathrm{J}$ Hazard Mater 197: 229-236.
30. Roldán R, Sánchez-Sánchez M, Sankar G, Romero-Salguero FJ, JiménezSanchidrián C (2007) Influence of pH and Si content on Si incorporation in SAPO-5 and their catalytic activity for isomerisation of $n$-heptane over $\mathrm{Pt}$ loaded catalysts. Micropor Mesopor Mater 99: 288-298.

31. Niwa M, Katada K (1997) Measurements of acidic property of zeolites by temperature programmed desorption of ammonia. Catal Surv Jpn 1: 215-226.

32. Suzuki K, Aoyagi Y, Katada N, Choi M, Ryoo R, et al. (2008) Acidity and catalytic activity of mesoporous ZSM-5 in comparison with zeolite ZSM-5, AlMCM-41 and silica-alumina. Catal Today 132: 38-45.

33. Borade RB, Clearfield A (1994) A comparative study of acidic properties of SAPO-5, SAPO-11, SAPO-34 and SAPO-37 molecular sieves. J Mol Catal 88 : 249-266.

34. Sastre G, Lewis DW, Richard C, Catlow A (1997) Modeling of silicon substitution in SAPO-5 and SAPO-34 molecular sieves. J Phys Chem B 101: 5249-5262.

35. Li Z, Martínez-Triguero J, Yu J, Corma A (2015) Conversion of methanol to olefins: Stabilization of nanosized SAPO-34 by hydrothermal treatment. J Catal 329: $379-388$

36. Wei $Y$, Zhang D, He Y, Xu L, Yang Y, et al. (2007) Catalytic performance of chloromethane transformation for light olefins production over SAPO-34 with different Si content. Catal Lett 114: 30-35

37. Wang L, Guo C, Yan S, Huang X, Li Q (2003) High-silica SAPO-5 with preferred orientation: synthesis, characterization and catalytic applications. Micropor Mesopor Mater 64: 63-68.

38. Sinha AK, Sainkar S, Sivasanker S (1999) An improved method for the synthesis of the silicoaluminophosphate molecular sieves, SAPO-5, SAPO-11 and SAPO-31. Micropor Mesopor Mater 31: 321-331.

39. Yang C, Gong C, Peng T, Deng K, Zan L (2010) High photocatalytic degradation activity of the polyvinyl chloride (PVC)-vitamin C (VC)-TiO2 nano-composite film. J Hazard Mater 178: 152-156.

40. Zhu Q, Kondo JN, Ohnuma R, Kubota Y, Yamaguchi M, et al. (2008) The study of methanol-to-olefin over proton type aluminosilicate $\mathrm{CHA}$ zeolites. Micropor Mesopor Mater 112: 153-161.

41. Dahl IM, Wendelbo R, Andersen A, Akporiaye D, Mostad H, et al. (1999) The effect of crystallite size on the activity and selectivity of the reaction of ethano and 2-propanol over SAPO-34. Micropor Mesopor Mater 29: 159-171. 